Revista Brasileira de Agricultura Irrigada v.13, nº.5, p. 3683 - 3690, 2019

ISSN 1982-7679 (On-line)

Fortaleza, CE, INOVAGRI - http://www.inovagri.org.br

DOI: $10.7127 /$ rbai.v13n5001131

Protocolo 1131.19 - 30/03/2020Ａprovado em 09/04/2020

\title{
CRESCIMENTO E PRODUÇÃO DE PIMENTÃo UTILIZANDO ÁGUA RESIDUÁRIA DOMÉSTICA TRATADA
}

\author{
Fiama Beatriz Tavares ${ }^{1}$, Ana Carla Rodrigues da Silva², Cleyton dos Santos Fernandes ${ }^{3}$, Karidja
} Kalliany Carlos de Freitas Moura ${ }^{4}$, Kaline Dantas Travassos ${ }^{5}$

\begin{abstract}
RESUMO
Na região semiárida do nordeste do Brasil, o reuso pode se constituir em uma fonte alternativa de água, matéria orgânica e nutrientes para as plantas, com possibilidade de assegurar e incrementar a produção agrícola durante as estiagens prolongadas, em especial ao nível da agricultura familiar, contribuindo para a fixação do homem no campo. Objetivou-se com a presente pesquisa avaliar o crescimento e a produção do pimentão em sistema semi-hidropônico utilizando efluente de esgoto doméstico tratado. $\mathrm{O}$ experimento foi conduzido em ambiente protegido em delineamento experimental inteiramente casualizado. Os tratamentos resultaram da mistura de duas fontes de água, sendo uma de abastecimento (AA) e outra residuária (AR), resultando em: T1- 100\% AA (testemunha); T2- 25\% AR + 75\% AA; T3- 50\% AR + 50\% AA; T4- 75\% AR + 25\% AA; T5-100\% AR. Os resultados indicaram que o efluente de esgoto doméstico tratado incrementou o diâmetro do caule, o número de folhas, o número de frutos por planta e a produção das plantas de pimentão, sendo os melhores resultados obtidos nas plantas irrigadas com 100\% da água residuária. Com base nesses resultados, pode-se concluir que efluente de esgoto doméstico tratado pode ser utilizado como fonte hídrica e nutricional para a cultura do pimentão.
\end{abstract}

Palavras-chave: capsicum annuum L., sustentabilidade, hidroponia.

\section{GROWTH AND YIELD OF BELL PEPPER USING TREATED SEWAGE WATER}

\footnotetext{
ABSTRACT

${ }^{1}$ Graduada em Agronomia pela Universidade Federal Rural do Semi Árido, Departamento de Ciências Agrárias, Rua Francisco das Chagas Celedônio 1245, Limoeiro do Norte - CE, Brasil, fiama_beatryz@hotmail.com

2 Mestre em Ciência do Solo pela Universidade Federal do Ceará, Departamento de ciência do solo, Rua Francisco Pitombeira 199, Sitio Espinho, Limoeiro do Norte - CE, Brasil, anacrodrigues9148@ hotmail.com

${ }^{3}$ Doutorando em Fitotecnia pela Universidade Federal Rural do Semi Árido, Departamento de Fitotecnia, Rua Francisco Mota 572, Pres. Costa e Silva, Mossoró - RN, Brasil, cleyton1959@hotmail.com

${ }^{4}$ Pós-doutorado em Ciências Agrárias pela Universidade Federal Rural do Semi Árido, Departamento de Ciência do Solo, Professora e Coordenadora de Pesquisa e Extensão da Faculdade Católica do Rio Grande do Norte, Praça Dom João Costa, Santo Antônio, Mossoró-RN, Brasil, extensao@ catolicadorn.com.br

${ }^{5}$ Pós-doutoranda em Manejo Solo e água pela Universidade Federal Rural do Semi Árido, Departamento de Ciência do Solo, Rua Francisco Mota Bairro 572, Pres. Costa e Silva, Mossoró - RN, Brasil, kalinedantas@yahoo.com.br
} 
In the semi-arid region of northeastern Brazil, reuse can be an alternative source of water, organic matter and nutrients to plants, with possibilities to ensure and increase agricultural production during long dry periods, in particular at the level of family agriculture, contributing to the settlement of man in the countryside. The aimed of this research was to evaluate the growth and production of bell pepper in a semi-hydroponic system using treated domestic sewage effluent. The experiment was carried out in a greenhouse in a completely randomized experimental design. The treatments resulted from the mixture of two sources of water, being one of supply (AA) and the other for waste (AR), resulting in: T1- 100\% AA (control); T2- 25\% AR + 75\% AA; T3- 50\% AR + 50\% AA; T4- 75\% $\mathrm{AR}+25 \% \mathrm{AA} ; \mathrm{T} 5-100 \% \mathrm{AR}$. The results indicated that the treated domestic sewage effluent increased the diameter of the stem, the number of leaves, the number of fruits per plant and the production of bell pepper plants, with the best results obtained in plants irrigated with $100 \%$ of wastewater. Based on these results, it can be concluded that treated domestic sewage effluent can be used as a water and nutritional source for the cultivation of bell pepper.

Keywords: capsicum annuит L , sustainability, hydroponics.

\section{INTRODUÇÃO}

O pimentão (Capsicum annuum) é uma Solanácea originária da América central, ocorrendo formas silvestres no México, América Central e América do Sul (Souza et al., 2011). A cultura do pimentão é difundida em todo o Brasil, e possui grande importância econômica. Segundo a FAO (2017), a área estimada de plantio é 19 mil hectares, com produção acima de 420 mil toneladas por ano. É uma hortaliça com boa adaptação às condições do Semiárido, onde no Nordeste, destacam-se como principais produtores os estados de Pernambuco, Paraíba, Ceará e Bahia em ordem decrescente (NASCIMENTO, 2014).

A necessidade hídrica do pimentão é de uma distribuição de água regular durante o ciclo, porém o excesso de umidade pode causar danos à cultura e o déficit hídrico pode provocar abortamento e queda de flores, sendo um dos principais fatores limitantes de altas produtividades (NASCIMENTO, 2014). Contudo, existe a necessidade de controle de perdas e desperdícios, onde se insere o reuso de água. Telles (2011) destaca que o interesse pelo uso das águas residuárias se deu devido ao avanço do conhecimento sobre o potencial e as limitações do reuso agrícola e suas vantagens, tais como controle da poluição; racionalização do uso da água, economia de fertilizantes, reciclagem de nutrientes, aumento da produção agrícola, e cobrança pelo uso da água e pelo lançamento de esgotos.

O uso de águas residuárias é altamente difundido no setor agrícola e, tal prática, além de permitir a conservação dos corpos hídricos aporta consideráveis quantidades de nutrientes ao solo, melhorando sua fertilidade, aumentando a produtividade das culturas e reduzindo custos (MEDEIROS et. al., 2015).

$\mathrm{O}$ aproveitamento da água residuária vem sendo utilizado como estratégia eficaz no convívio com a escassez de recursos hídricos em regiões áridas e semiáridas (AZEVEDO et al., 2013).

No contexto da necessidade de pesquisas e estudos para viabilizar o reuso da água, a hidroponia e/ou semi-hidroponia surge como alternativa de aproveitamento dos efluentes, tendo como vantagens, a redução do lançamento em cursos hídricos, a ciclagem dos nutrientes residuais do processo de tratamento, a possibilidade de instalação da infraestrutura necessária próxima à estação de tratamento, reduzindo custos com transporte do efluente, bem como, a mitigação adicional de riscos a saúde, ao minimizar o contato efluente-planta e o agricultor (CUBA et al., 2015).

Luz et al. (2011) afirma que hidroponia é a ciência de cultivar plantas sem solo, onde as raízes recebem uma solução nutritiva balanceada que contém água e todos os nutrientes essenciais ao desenvolvimento da planta, facilitando obter-se um controle mais adequado da nutrição da hortaliça produzida. 


\section{CRESCIMENTO E PRODUÇÃO DE PIMENTÃ̃ UTILIZANDO ÁGUA RESIDUÁRIA DOMÉSTICA TRATADA}

De acordo com Wendling et al. (2005), o sistema semi-hidropônico é uma alternativa para a produção de hortaliças, pois não é necessário o uso de energia elétrica funcionando por nível. A quantidade de água consumida é bem menor se comparada ao sistema convencional pois este sistema faz uso de solução nutritiva em conjunto com substrato sólido inerte (areia, argila expandida, vermiculita, bagaço de cana-de-açúcar, fibra de coco, serragem, entre outros) que mantém a umidade nas calhas sendo de suma importância para o crescimento e desenvolvimento das plantas. Além de calhas, podem ser utilizados outros tipos de recipiente para o substrato, como por exemplo, vasos plásticos, entre outros.

Os substratos utilizados no sistema de cultivo semi-hidropônico, mais do que exercer a função de suporte às plantas, proporcionam adequado suprimento de ar e água ao sistema radicular (SILVA, et al 2015).

Diante o exposto, objetivou-se com o presente trabalho avaliar o crescimento e a produção do pimentão em sistema semihidropônico utilizando água de esgoto doméstico tratado e água de abastecimento em diferentes proporções.

\section{MATERIAL E MÉTODOS}

O trabalho foi realizado em ambiente protegido no Departamento de Ciências Ambientais da Universidade Federal Rural do Semi-Árido (UFERSA), situado no município

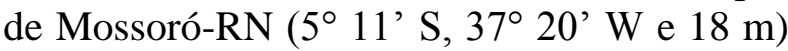
(Figura 1).

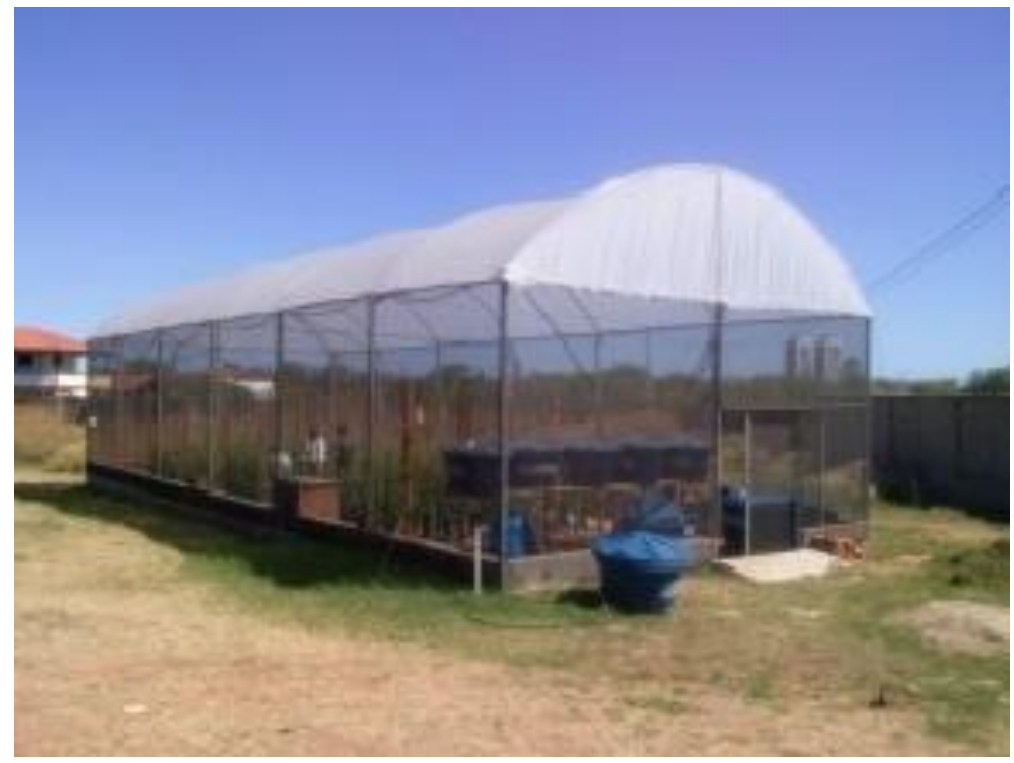

Figura 1 - Local de condução do experimento.

O clima predominante na área onde foi conduzido o ensaio é classificado como Tropical de Zona Equatorial, com três subtipos de clima (semiárido brando, semiárido mediano e semiárido forte) (DINIZ; PEREIRA, 2015), apresentando uma precipitação média de $673,9 \mathrm{~mm}^{\mathrm{ano}}{ }^{-1}$ e uma média anual de temperatura de $27{ }^{\circ} \mathrm{C}$ (CARMO FILHO; OLIVEIRA, 1995).

As mudas de pimentão (cv. Margarita) foram produzidas em bandejas de poliestileno expandido de 128 células preenchidas com substrato de fibra de coco (Golden Mix ${ }^{\circledR}$ ). O transplantio das mudas foi realizado aos 15 dias após a semeadura, transplantando-se duas mudas de pimentão por cada unidade experimental.

Cada unidade experimental foi composta por dois vasos plásticos de $12 \mathrm{dm}^{3}$, contendo uma camada de $2 \mathrm{~cm}$ de brita em sua parte inferior, recoberta com telado de nylon e preenchidos com $8 \mathrm{~kg}$ de fibra de coco. Os vasos foram posicionados de forma que as plantas ficassem espaçadas $0,50 \mathrm{~m}$ nas fileiras 
e 1,00 m entre plantas. A área experimental foi constituída por 6 fileiras de plantas, sendo as duas fileiras da extremidade designadas como bordadura.

A condução da cultura foi feita com espaldeiras verticais de $2 \mathrm{~m}$ de altura e com auxílio de fita de ráfia, eliminando-se os excessos de brotações laterais por meios de podas. O trabalho foi conduzido em sistema semi-hidropônico, onde a água residuária teve contato apenas com o substrato. Como substrato utilizou-se fibra de coco. Eram feitas duas irrigações diárias, sendo a primeira pela manhã e a segunda à tarde. Em cada irrigação, aplicou-se um volume de água suficiente para elevar a umidade próxima da máxima capacidade de retenção de água. As soluções das caixas eram trocadas semanalmente. O delineamento experimental foi o inteiramente casualizado com 5 tratamentos e 5 repetições, totalizando 25 unidades experimentais (Figura 2). Os tratamentos constaram da mistura de duas fontes de água, sendo uma de abastecimento (AA) e outra residuária (AR), resultando em: T1- 100\% AA (testemunha); $\mathrm{T} 2-25 \% \mathrm{AR}+75 \% \mathrm{AA} ; \mathrm{T} 3-50 \% \mathrm{AR}+50 \%$ AA; T4- 75\% AR + 25\% AA; T5-100\% AR.

A água de abastecimento foi proveniente do campus da UFERSA, enquanto que a água residuária (água de esgoto doméstico tratado) foi coletada no Projeto de Assentamento Soledade, localizada em Apodi - RN. As características químicas das águas utilizadas no experimento estão descritas na Tabela 1.

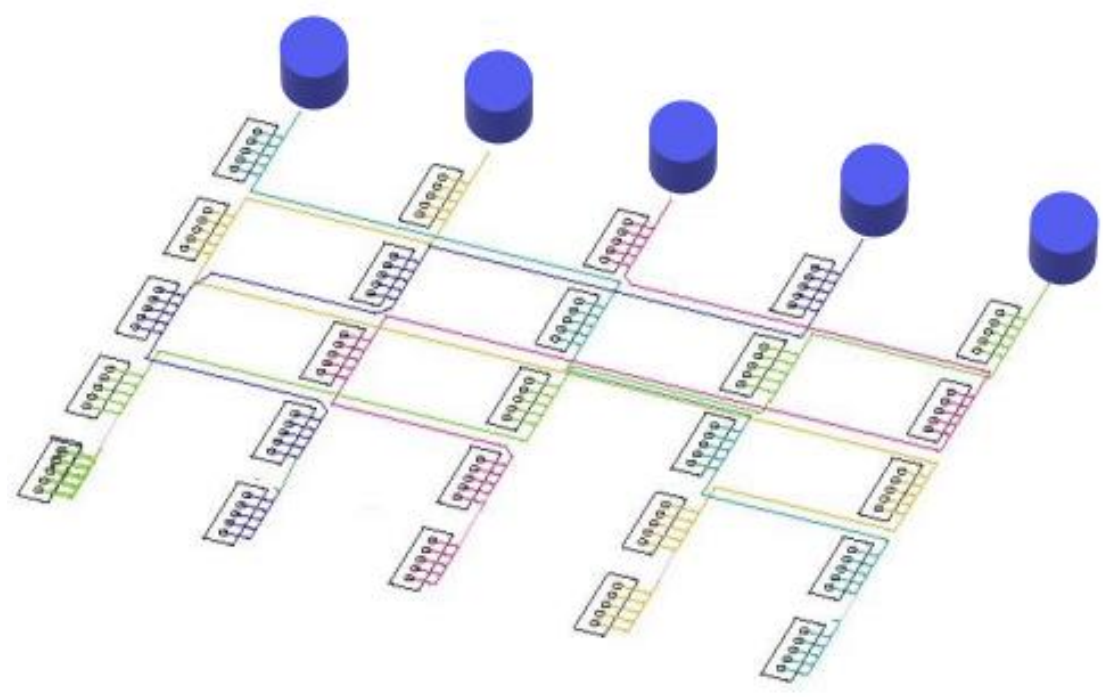

Figura 2 - Esquema representativo do croqui do experimento.

Tabela 1 - Caracterização das águas utilizadas no experimento.

\begin{tabular}{cccccc}
\hline Características & $100 \% \mathrm{AA}$ & $\begin{array}{c}25 \% \mathrm{AR}+ \\
75 \% \mathrm{~A} \mathrm{~A}\end{array}$ & $\begin{array}{c}50 \% \mathrm{AR} \\
+50 \% \\
\mathrm{AA}\end{array}$ & $\begin{array}{c}75 \% \mathrm{AR} \\
+25 \% \mathrm{AA}\end{array}$ & $\begin{array}{c}100 \% \\
\mathrm{AR}\end{array}$ \\
\hline $\mathrm{pH}$ & 8,10 & 7,70 & 7,70 & 7,60 & 7,60 \\
Condutividade elétrica $\left(\mathrm{ds} \mathrm{m}{ }^{-1}\right)$ & 0,57 & 0,57 & 0,77 & 0,97 & 0,96 \\
Turbidez $(\mathrm{UNT}$ & 0,19 & $27,8-$ & 35,60 & 47,80 & 70,00 \\
Coliformes totais $\left(\mathrm{NMP} \mathrm{ml}^{-1}\right)$ & $<3,00$ & 230 & 560 & $>1100$ & $>1100$ \\
Sódio $\left(\mathrm{mmol}_{\mathrm{c}} \mathrm{L}^{-1}\right)$ & 9,80 & 10,00 & 8,60 & 7,60 & 7,10 \\
Potássio $\left(\mathrm{mmol}_{\mathrm{c}} \mathrm{L}^{-1}\right)$ & 0,90 & 1,50 & 1,70 & 2,10 & 2,80 \\
Cálcio $\left(\mathrm{mmol}_{\mathrm{c}} \mathrm{L}^{-1}\right)$ & 0,40 & 0,50 & 0,50 & 0,40 & 0,60 \\
Nitrato de prata $\left(\mathrm{mmol}_{\mathrm{c}} \mathrm{L}^{-1}\right)$ & 1,10 & 1,20 & 1,60 & 1,40 & 1,60 \\
Bicarbonato $\left(\mathrm{mmol}_{\mathrm{c}} \mathrm{L}^{-1}\right)$ & 3,30 & 3,00 & 2,60 & 1,50 & 2,40 \\
\hline
\end{tabular}

As mensurações das variáveis foram realizadas durante a colheita $\mathrm{e}$ as características avaliadas foram: altura de plantas (AP) (com auxílio de fita métrica, 


\section{CRESCIMENTO E PRODUÇÃO DE PIMENTÃo UTILIZANDO ÁGUA RESIDUÁRIA DOMÉSTICA TRATADA}

considerando-se a distância do nível do substrato ao topo da planta), diâmetro do caule (DC) (com auxílio de paquímetro digital), número de folhas (NF), número de frutos por planta (NFP) (correspondeu ao número dos frutos comerciais, expresso em frutos planta-1) e a produtividade (PROD) (obtida pelo peso médio por planta e extrapolada para hectares, considerando o espaçamento utilizado). Os dados foram submetidos à análise de variância e quando apresentaram significância, verificou-se a diferença por meio de análise de regressão.

Todas as análises foram feitas com auxílio do software estatístico SISVAR (FERREIRA, 2011).

(A)

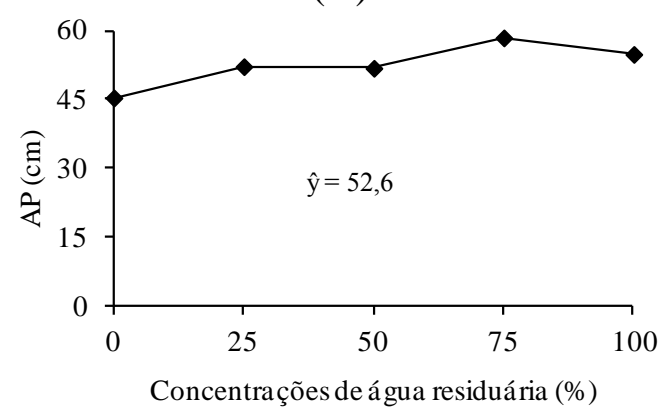

(C)

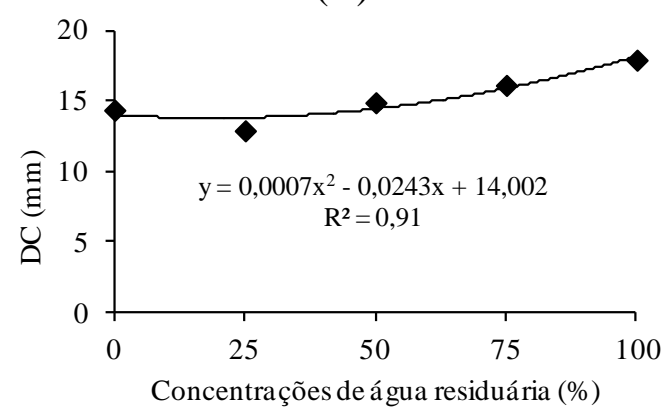

(E)

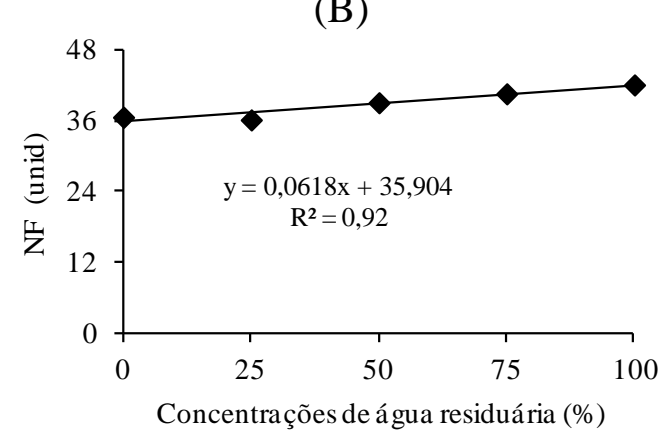

(D)

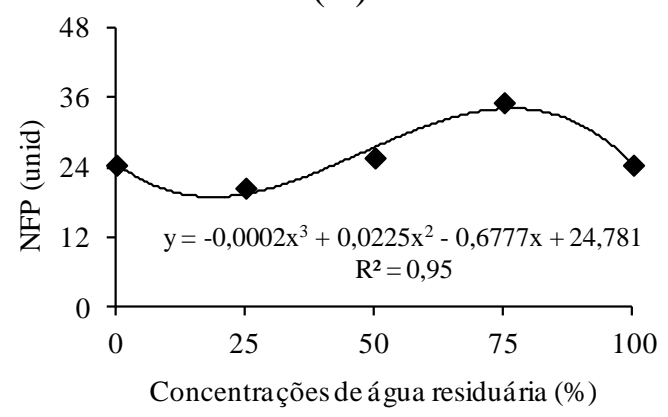

PROD foram afetados significativamente pela adição de concentrações de água de esgoto doméstico tratado. A AP foi a única variável que não foi influenciada pela adição da água residuária, apresentando média de $52,6 \mathrm{~cm}$ (Figura 3A). Esses resultados corroboram com os obtidos por Henrique et al. (2005) que ao estudarem a utilização de esgotos tratados no desenvolvimento da cultura pimentão (Capsicum annuum L.) observaram efeito dos tratamentos para os parâmetros avaliados, sendo a exceção apenas a altura das plantas, onde não houve variação significativa.

(B)

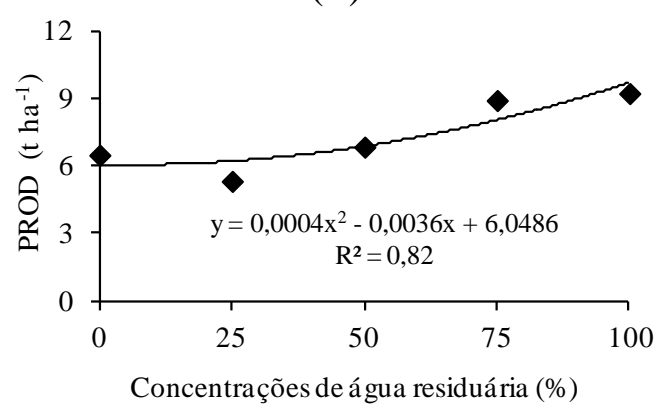

Figura 3 - Altura de plantas (AP) (A), número de folhas (NF) (B), diâmetro do caule (DC) (C), número de frutos por planta (NFP) (D) e produção (PROD) (E) de pimentão irrigado com diferentes concentrações de esgoto doméstico tratado. 
As concentrações de esgoto doméstico tratado promoveram incremento linear no NF do pimentão, chegando a atingir o número máximo de folhas (41 folhas) na concentração de $100 \%$ do efluente (Figura 3B). De acordo com Rigon et al. (2011) estes resultados podem ser atribuídos ao fato do efluente utilizado ser rico em nitrogênio, nutriente este que favorece o desenvolvimento vegetativo das plantas, como foi observado nesta pesquisa.Verificou-se resposta quadrática para o DC de pimentão em função da aplicação de diferentes concentrações de esgoto doméstico tratado, com os valores decrescendo até a concentração de $25 \%$ da água residuária. A partir dessa concentração, o DC foi incrementado, sendo observado $\mathrm{O}$ valor máximo $(18,5 \mathrm{~mm})$ quando se realizou $100 \%$ da irrigação com a água residuária (Figura 3C). Resultados semelhantes aos obtidos no presente estudo foram constatados por Sousa et al. (2006) em plantas de pimentão e Silva et al. (2014) em plantas de pimenta, uma vez que esses autores também verificaram que a irrigação com esgoto doméstico tratado incrementou o DC das referidas culturas.

O NFP apresentou resposta cúbica em função da irrigação irrigação com diferentes concentrações de esgoto doméstico tratado, sendo o número máximo de frutos (37 frutos por planta) obtido no tratamento que foi irrigado com $75 \%$ da água residuária (Figura 3D). Esses resultados são difíceis de serem explicados, uma vez que do ponto de vista biológico, não existe uma explicação para esse comportamento. Ainda em relação a figura $3 \mathrm{D}$, verificou-se que o NFP obtido nas plantas irrigadas com $75 \%$ de esgoto doméstico tratado foi $50 \%$ superior ao obtido nas plantas irrigadas com água de abastecimento. Sousa et al. (2006) também verificaram que a irrigação com esgoto doméstico tratado incrementa o NFP, corroborando assim com os resultados obtidos no presente estudo.

A PROD seguiu o mesmo comportamento do DC, com os valores decrescendo até a concentração de $25 \%$ da água residuária. A partir dessa concentração a PROD foi incrementada, atingindo valor máximo $\left(9,6 \mathrm{tha}^{-1}\right)$ nas plantas irrigadas com
$100 \%$ de água residuária (Figura 3E). Há estudos que indicam que efluente de esgoto doméstico tratado incrementa a produção de plantas da família das solanáceas, como demonstrado por Queiroz et al. (2015). Os referidos autores verificaram que quando o tomateiro é irrigado com esta fonte hídrica pode apresentar desempenho agronômico superior ao obtido em plantas que receberam fertilização convencional. Ainda de acordo com esses autores, tais resultados se devem ao fato do fornecimento dos nutrientes presentes no efluente serem disponibilizados de forma parcelada e gradual, favorecendo assim um bom desenvolvimento das plantas, e consequentemente, a sua produção.

Em relação a qualidade microbiológica, pode-se assegurar que os frutos são livres de contaminantes, pois devido o trabalho ter sido conduzido em sistema semi-hidropônico, tanto a parte aérea quanto a produtiva não tiveram contato direto com a água de residuária. Segundo Marouelli e Silva (1998), dependendo do grau de contaminação, tipo de cultura ou sistema de irrigação adotado, a água contaminada por patógenos pode ser utilizada sem maiores problemas na irrigação. Os referidos autores afirmam ainda que hortaliças com superfície lisa, como tomate, berinjela e pepino, não apresentam condições favoráveis à retenção e sobrevivência dos microrganismos patógenos, o que se enquadra na realidade do pimentão.

\section{CONCLUSÕES}

A irrigação com diferentes concentrações de esgoto doméstico tratado incrementou o crescimento e produção do pimentão, em que a concentração de $100 \%$ promoveu os melhores resultados.

O sistema semi-hidropônico mostrou-se eficaz em proporcionar um melhor controle da cultura, em relação a pragas, doenças, economia de água, otimização do espaço, além de facilitar os tratos culturais.

Efluente de esgoto doméstico tratado pode ser utilizado como fonte hídrica $\mathrm{e}$ nutricional para a cultura do pimentão. 


\section{REFERÊNCIAS}

ASSOCIAÇÃO BRASILEIRA DE NORMAS TÉCNICAS. NBR 13969: Reuso da água. Disponível em: <https://www.abntcatalogo.com.br/norma.asp x?ID=3633>. Acesso em: 23 de janeiro de 2019.

AZEVEDO, J.; DUTRA, I. C.B.; COSTA, F.G.B.; BATISTA, R. O.; COSTA, L. R. Alterações químicas de Cambissolo fertirrigado com água residuária doméstica tratada. Revista Agropecuária Científica no Semiárido, v. 9, n. 2, p. 66-76, 2013.

BASTOS, R. K. X.; BEVILACQUA, P. D.; SILVA, C. A. B.; DORNELAS, F. L.; ASSUNÇÃO, F. A. L.; RIOS, E. N.; SILVA, A. F. S.; FREITAS, A. S.; COSTA, G. S. Tratamento de esgotos sanitários e usos múltiplos de efluentes. Revista Brasileira de Engenharia Agrícola e Ambiental, v.9, (Suplemento), p.164-170, 2005.

CARMO FILHO, F.; OLIVEIRA, O. F. Mossoró: um município do semi-árido nordestino, caracterização climática e aspecto florístico. Mossoró: ESAM, 1995. 62p. (Coleção Mossoroense, série B).

COSTA, Z. V. B.; GURGEL, M. T.; COSTA, L. R.; ALVES, S. M. C.; FERREIRA NETO, M.; BATISTA, R. O. Efeito da aplicação de esgoto doméstico primário na produção de milho no assentamento Milagres (Apodi-RN). Revista Ambiente \& Água, v.9, n.4, p.737-751, $2014 . \quad$ http://dx.doi.org/10.4136/ambiagua. 1417

CUBA, R. S.; CARMO, J. R.; SOUZA, C. F.; BASTOS, R. G. Potencial de efluente de esgoto doméstico tratado como fonte de água $\mathrm{e}$ nutrientes no cultivo hidropônico de alface. Revista Ambiente \& Água, v.10, n.3, p.574586, 2015. http://dx.doi.org/10.4136/ambiagua. 1575
DINIZ, M.T.M.; PEREIRA, V.H.C Climatologia do estado do Rio Grande do Norte, Brasil: sistemas atmosféricos atuantes e mapeamento de tipos de clima. Boletim Goiano de Geografia, v.35, n.3, p.488-506, 2015.

FAO. Faostat - Statistics Database. Disponivel em: < http://www.fao.org/statistics/en/>, Acesso: 22 de jan. 2019.

FERREIRA, D. F. Sisvar: a computer statistical analysis system. Ciência e Agrotecnologia, v.35, n.6, p.1039-1042, 2011. http://dx.doi.org/10.1590/S141370542011000600001

HENRIQUE, I. N.; SOUSA, J. T. DE; DUARTE LEITE, V.; FIDELES, J.; PIRES DANTAS, J. Utilização de esgotos tratados no desenvolvimento da cultura pimentão. Congresso Brasileiro de Engenharia Sanitária e Ambiental, 23, Campo Grande, 2005.

LUZ, J. M. Q.; COSTA, C. C.; GUERRA, G. M. P.; SILVA, M. A. D.; HABER, L. L. Efeito da variação da solução nutritiva no cultivo hidropônico de rúcula. Revista Verde de Agroecologia e Desenvolvimento Sustentável. Pombal-PB, v. 6, n. 3, p.76-82, 2011.

MAROUELLI, W. A.; SILVA, H. R. Aspectos sanitários da água para fins de irrigação. Brasília: EMBRAPA Hortaliças, 1998. 7p. Comunicado Técnico.

MEDEIROS, S. S., SOARES, A. A., FERREIRA, P. A., NEVES, J. C. L., MATOS, A. T.; SOUZA, J. A. A. Utilização de água residuária de origem doméstica na agricultura: Estudo das alterações químicas do solo. Revista Brasileira de Engenharia Agrícola e Ambiental, v.9, n.4, p.603-612, 2015. http://dx.doi.org/10.1590/S141543662005000400026 
NASCIMENTO, W. M. Produção de Sementes de Hortaliças - Volume I. 1. ed., 2014. v. 1. 315p.

QUEIROZ, A. A. Q.; QUEIROZ, S. O. P. DE; ARAGÃO, C. A. Reuso de efluentes domésticos na irrigação por gotejamento do tomateiro. Pesquisa Agropecuária Pernambucana, v.20, n.1, p.36-42, 2015.

RIGON, J. P. G., BRITO NETO, J. F., CAPUANI, S., BELTRÃO, N. E. M., \& SILVA, F. V. F. Utilização de nitrogênio e níquel durante o crescimento do algodão. Enciclopédia Biosfera, v.7, n.13, p.10191026, 2011.

SEBRAE, Serviço Brasileiro de Apoio às Micro e Pequenas Empresas. Série Agricultura Familiar Coleção Passo a Passo - Pimentão, 2012.

SILVA, L. L.; CARVALHO, C. M.; SOUZA, R. P. F.; FEITOSA, H. O.; FEITOSA, S. O.; GOMES FILHO, R. R. Utilização de efluentes domésticos no crescimento da pimenta (Capsicum chinense), cultivar tekila bode vermelha. Agropecuária Técnica, v.35, n.1, p.121-133, 2014.

SILVA, K. M. P. Concentration of nutrient solution of melon growing in semi - hydroponic system. $\quad 2015 . \quad 61$ f. Dissertação (Mestrado em Manejo de Solo e água) Universidade Federal Rural do SemiÁrido, Mossoró.

SOUSA, J. T.; CEBALLOS, B. S. O.; HENRIQUE, I. N.; DANTAS, P. J.; LIMA, S. M. S. Reúso de água residuária na produção de pimentão (Capsicum annuum L.). Revista Brasileira de Engenharia Agrícola e Ambiental, v.10, n.1, p.89-96, 2006.

SOUZA, V. F.; MAROUELLI, W. A.; COELHO, E. F.; PINTO, J. M.; COELHO FILHO, M. A. Irrigação e fertirrigação em fruteira e hortaliças. Brasília: Embrapa, 2011. p. 721-736

TELLES, D. D. Aspectos da utilização de corpos de d’água que recebem esgoto sanitário na irrigação de culturas agrícolas. Esgoto sanitário: coleta, transporte, tratamento e reuso agrícola. 2. ed. São Paulo: Blucher, 2011. p.507-528.

WENDLING, I.; FERRARI, M. P.; DUTRA, L. F. Produção de mudas de corticeira-do-mato por miniestaquia a partir de propágulos juvenis. Colombo-PR: Embrapa Florestas, 2005. 5p. (Comunicado Técnico, 130). 